\title{
Epidermal Growth Factor (EGFR) copy number aberrations in esophageal and gastro-esophageal junctional carcinoma
}

Åsa Dahle-Smith 1*, David Stevenson ${ }^{2}$, Doreen Massie ${ }^{2}$, Graeme I. Murray ${ }^{1,3}$, Susan J. Dutton ${ }^{4}$, Corran Roberts ${ }^{4}$, David Ferry ${ }^{5}$, Aileen Osborne ${ }^{6}$, Caroline Clark ${ }^{2}$, Russell D. Petty ${ }^{1 \dagger}$ and Zosia Miedzybrodzka ${ }^{1,2+}$

\begin{abstract}
Background: Clinical trials of agents targeting epidermal growth factor receptor (EGFR) in esophageal carcinoma (EC) have indicated a minority subgroup responsive to anti-EGFR therapies. Other investigations suggest increases in EGFR copy number are associated with poor prognosis in EC, but have used a variety of different techniques and tested numbers remain small. A validated assay for EGFR copy number in EC is needed, to allow investigation of EGFR copy number gain as a predictive biomarker for the anti-EGFR responsive subgroup of patients. We developed a scoring system in EC based upon established systems for EGFR fluorescence in-situ hybridisation (FISH) in lung cancer, and applied this in a series of 160 UK patients with advanced EC.

Results: Dual colour FISH on formalin fixed paraffin embedded (FFPE) biopsies were scored independently by two operators as: disomy (score $=1)$, low trisomy $($ score $=2)$, high trisomy $($ score $=3)$, low polysomy $($ score $=4)$, high polysomy (score $=5$ ) and amplification (score =6). EGFR FISH positive cases (scores 5 and 6) were found in 32/160 (20 \%) tumours, with high polysomy in 22 (13.8\%) and amplification in 10 (6.3\%). Two independent operator scores for FISH positivity were $100 \%$ concordant. EGFR FISH positive status was not associated with clinic-pathological features. EGFR amplification was associated with worse survival ( $H R=2.64,95 \% \mathrm{Cl} 1.04$ to $6.71, p=0.03)$.

Conclusion: Our FISH scoring system for EGFR in advanced EC identifies a significant subgroup (20.0 \%) of FISH positive patients. EGFR amplification, which is found in $6.3 \%$, is associated with poor survival. It is not known if there is a role for EGFR targeted treatment in this subgroup of patients, however we are now utilising this EGFR FISH assay and scoring system in biopsies from clinical trials utilising anti-EGFR targeted therapies.
\end{abstract}

Keywords: EGFR Copy Number, Esophageal Carcinoma, Esophago-gastric junctional carcinoma

\section{Background}

Esophageal carcinoma (EC) is the eighth most common malignancy worldwide [1]. The incidence of esophageal adenocarcinoma (EA), has rapidly increased in the USA, Europe and Australia over the last 30-50 years [2]. Esophageal squamous cell carcinoma (ESCC) remains common in Western countries and is the most frequent histological subtype in the developing world, and the Middle and Far East [1, 3-5]. Despite advances in imaging modalities, surgical technique, chemotherapy

\footnotetext{
* Correspondence: asadahle-smith@nhs.net

${ }^{\dagger}$ Equal contributors

'Division of Applied Medicine, University of Aberdeen, Aberdeen AB25 2ZD, UK

Full list of author information is available at the end of the article
}

and radiotherapy, survival remains poor, with USA and European five year survival rates of $24.5-39.6 \%$ in patients presenting with localised disease and 9.8-17.5\% in the overall EC population [6, 7]. Chemotherapy confers only modest benefit in metastatic disease with median survival of only 9-11 months [8], and only half of patients will complete first line treatment due to toxicity or disease progression, although $40 \%$ of patients may be fit for second line treatment $[9,10]$.

There has been a recent paradigm shift in the treatment of esophagogastric cancer. In the TOGA study, Bang and colleagues demonstrated survival benefit using the HER-2 monoclonal antibody trastuzumab over placebo with capecitabine/5-FU and cisplatin chemotherapy in patients 
with advanced gastro-esophageal junction or gastric adenocarcinomas overexpressing HER-2 by immunohistochemistry or HER-2 gene amplification by FISH [11].

The primary end point of overall survival was met with median OS of 13.8 months in the trastuzumab arm compared to 11.1 months in the chemotherapy alone arm, $p=0.046$. Patients whose tumours had either very high HER-2 over expression (IHC3+) or HER-2 amplification confirmed by FISH, achieved a median survival of 17.9 months when treated with trastuzumab plus chemotherapy, compared to median survival of 12.3 months when treated with chemotherapy alone, HR 0.57 (95 \% CI 0.41-0.81) [11].

Following this proof of concept of a role for targeted therapies in esophagogastric cancer, the clinical utility of novel agents targeting other growth factors have been investigated in EC.

There are two main classes of targeted therapy; small molecule tyrosine kinase inhibitors which act intracellularly on tyrosine kinases to prevent induction of downstream signalling pathways; and monoclonal antibodies which either compete with extracellular ligands to bind onto growth factor receptors or act directly on ligands to prevent ligand binding.

Targeted therapies against the Epidermal Growth Factor Receptor (EGFR) are in routine clinical use. Activation of the EGFR pathway stimulates intracellular signalling cascades including the RAF-MEK-ERK pathway which is involved in regulation of cell cycle progression, cell differentiation, proliferation and apoptosis, the subject of detailed reviews by Neuzillet et al. and McCrubrey et al. $[12,13]$. Activation of the EGFR pathway also initiates the PI3K-PTEN-Akt pathway, which has key roles in regulation of apoptosis and protein synthesis $[14,15]$. The EGFR and its ligands represent 'druggable' targets which when inhibited result in downregulation of growth factor pathways and thus anti-cancer effect. The tyrosine kinase inhibitor gefitinib has demonstrated survival benefit in EGFR mutated non-small cell lung cancer [16] and cetuximab, an anti-EGFR monoclonal antibody, improves survival in KRAS wild type colorectal cancer [17].

Recent trials of the anti-EGFR monoclonal antibodies cetuximab and panitumumab in combination with chemotherapy have not shown any overall survival benefit in EC $[18,19]$. The COG study, a phase III, randomised, double blinded trial of gefitinib, a tyrosine kinase inhibitor targeting EGFR, versus placebo in the second line setting of esophageal cancer patients did not demonstrate improvement in overall survival. However, median progression free survival with gefitinib was significantly improved from 1.1 to 1.57 months (HR $0.8,95 \%$ CI 0.66 to $0.96, p=0.02)$ as was disease control rate, $24.1 \%$ compared to $15.6 \%$ at eight weeks $(p=0.016)$ [20]. Patient reported outcomes were also significantly improved. This suggests an anti-EGFR therapy responsive subgroup and highlights the importance of developing a predictive biomarker for anti-EGFR treatment benefit [20].

Gene copy number changes are frequent in EC in comparison to other tumour types including tumours in the gastrointestinal tract, even in the stomach [21]. Previous studies of EGFR gene copy number changes have suggested an association with poor prognosis in EC [21]. We thus propose that EGFR gene copy number changes might prove useful as predictive biomarkers for targeted therapies against EGFR [22].

$E G F R$ copy number gain, including amplification, in esophageal and gastric cancers has been identified using several different methods, which used differing levels of gain for reporting EGFR amplification and inconsistent results regarding whether this confers a poor prognosis (Table 1) [23-32]. Differing classification systems for significant copy number gain or amplification, distinct biological differences between gastric cancer and EC, and some studies not assessing correlation between EGFR copy number and survival may account for reported disparities. In addition, the majority of previous studies have been small and undertaken in patients of differing ethnicities, and several studies were performed with technology that is no longer in widespread clinical use (Table 1) [23-32]. No previous study has provided a classification for EGFR copy number in EC to the degree that has become routine practice in other tumour types.

FISH is widely recognised as the "gold standard" diagnostic method for assessing gene copy number gain in human cancers. FISH for EGFR copy number alterations has been most extensively studied in formalin fixed paraffin embedded (FFPE) non-small cell lung cancer samples. Hirsch and colleagues [33] described four distinct categories in an analysis of 183 cases: disomy, trisomy, polysomy and amplification. Amplification was further classified as low (EGFR/ CEP7 ratio 2.1-3.0) or high (ratio >3.0). Significant correlation between EGFR gene copy number by FISH and EGFR protein expression by immunohistochemistry was identified $(p<0.001)$; high gene copy number also showed a trend towards poorer prognosis.

This principle of gene copy number classification in lung cancer was developed further by Cappuzzo et al, categorising EGFR FISH status into six categories with precise inclusion criteria of FISH positive cases comprising either high polysomy ( $\geq 40 \%$ of cells with $\geq 4$ copies of the EGFR gene) or amplification [34]. The concept of intratumoural heterogeneous amplification was also introduced, with the amplification criteria expanded from having an overall ratio of $>2.0$ to include either clustered EGFR signal with ratio of $\geq 2.0$ or $\geq 15$ EGFR copies in $\geq 10 \%$ cells analysed. In a multivariate analysis using this criteria, EGFR FISH positive tumour 
Table 1 Frequency of EGFR gene amplification in esophago-gastric cancer

\begin{tabular}{|c|c|c|c|c|c|c|}
\hline Histology & Ethnicity & Technique & Amplification classification & Amplification (\%) & Amplification impact on prognosis & Reference \\
\hline GC & European & Southern Blot & Not documented & $2 / 30(6.7 \%)$ & Not assessed & Lemoine 1991 [23] \\
\hline GC & Chinese & $\mathrm{FISH}$ & $\begin{array}{l}\geq 15 \text { EGFR copies in } \geq 10 \% \\
\text { tumour cells OR } \geq 40 \% \text { cells with } \\
\geq 4 \text { EGFR copies OR EGFR/CERP7 } \\
\text { ratio } \sim 1 \text { but cluster of } \geq 4 \text { EGFR } \\
\text { copies in } \geq 10 \% \text { cells OR EGFR/ } \\
\text { CERP7 ratio } \geq 2 \text { and cluster of } \\
\geq 4 \text { EGFR copies in } \geq 10 \% \text { cells }\end{array}$ & 20/69 (29 \%) & Not assessed & YK 2011 [24] \\
\hline GC & European & $\mathrm{FISH}$ & EGFR/ CEP 7 ratio $\geq 2.0$ & 4/82 (4.88 \%) & $\begin{array}{l}\text { Poorer survival of EGFR amplified } \\
\text { cases in multivariate analysis (HR } \\
4.82,95 \% \text { Cl 1.32-17.7, } p=0.0176 \text { ) }\end{array}$ & Kandel 2014 [25] \\
\hline ESCC & Japanese & Southern Blot & EGFR/ CEP 7 ratio $\geq 2.0$ & 9/42 (21.4\%) & Not assessed & Itakura 1994 [26] \\
\hline ESCC & Thai & $\mathrm{FISH}$ & $\begin{array}{l}\text { Low level: ratio 1.3-2.0, } \\
\text { High level: ratio }>2.0\end{array}$ & $8 / 15(49 \%)$ & $\begin{array}{l}\text { No significant difference in } \\
\text { survival in EGFR amplified cases }\end{array}$ & $\begin{array}{l}\text { Sunpaweravong } \\
2005[27]\end{array}$ \\
\hline ESCC & Japanese & $\mathrm{FISH} / \mathrm{CGH}$ & $\begin{array}{l}\text { FISH: EGFR/CEP } 7 \text { ratio } \geq 2.0 \text {; } \\
\text { CGH: }>4 \text { copies of EGFR gene }\end{array}$ & 16/244 (7 \%) & $\begin{array}{l}\text { No significant difference in } \\
\text { survival in EGFR amplified cases }\end{array}$ & Kato 2013 [28] \\
\hline ESCC & Japanese & $\mathrm{FISH}$ & $\begin{array}{l}\text { Low level: 3-10 EGFR signals/cell; } \\
\text { High level: cluster of EGFR } \\
\text { signals/>10 signals per cell }\end{array}$ & 15/83 (18.1\%) & $\begin{array}{l}\text { No significant difference in } \\
\text { survival in EGFR amplified cases }\end{array}$ & Hanawa 2006 [29] \\
\hline $\begin{array}{l}\text { EA and } \\
\text { ESCC }\end{array}$ & European & $\mathrm{CISH}$ & $\begin{array}{l}\text { CISH + ve: }>50 \% \text { cells with either } \\
\text { tight EGFR clusters or }>4 \text { EGFR } \\
\text { copies per cell }\end{array}$ & 2/16 (12.5\%) & Not assessed & Janmaat 2006 [30] \\
\hline EA & European & $\mathrm{FISH}$ & $\begin{array}{l}\text { Ratio } \geq 2.0 \text { or presence of tight } \\
\text { EGFR gene clusters }\end{array}$ & 7/112 (6.25 \%) & $\begin{array}{l}\text { Poorer survival of EGFR amplified } \\
\text { cases in multivariate analysis } \\
(p=0.0004)\end{array}$ & Marx 2010 [31] \\
\hline EA & $\begin{array}{l}\text { N. American } \\
\text { NOS }\end{array}$ & Southern Blot & Ratio $\geq 2.0$ & $7 / 87(8.0 \%)$ & Not assessed & Miller 2003 [32] \\
\hline
\end{tabular}

Abbreviations: CGH comparative genomic hybridisation, CISH chromogentic in situ hybridisation, FISH fluorescence in-situ hybridisation, GC gastric cancer, EA esophageal adenocarcinoma, ESCC esophageal squamous cell carcinoma

status demonstrated significantly improved response rates (36\% in EGFR FISH positive versus $3 \%$ in EGFR FISH negative patients; $p<0.001$ ) and overall survival (median overall survival 18.7 months in EGFR FISH positive versus 7.0 months in EGFR FISH negative patients; $p=0.003$ ) in 103 patients with nonsmall cell lung cancer being treated with the EGFR tyrosine kinase inhibitor gefitinib.

Varella-Garcia extended the EGFR FISH positive criteria to include larger and brighter EGFR signals compared to CEP7 signal in $>10 \%$ of tumour tissue with normal size EGFR signal in adjacent non- malignant cells, and recommended that fifty cells should be analysed in four distinct tumour areas [35]. An update providing guidance regarding sample storage and preparation was issued in 2009 [36].

In light of the potential importance of EGFR as a target in EC and EGFR copy number as a predictive biomarker, we adapted the consensus EGFR copy number analysis FISH assay used in non-small cell lung cancer as an assay for use in clinical trials and diagnostics in EC. Here we present the findings from applying this assay to FFPE tissue from 160 patients with advanced EC, approximately half of whom received second line treatment.

\section{Results}

\section{Patient characteristics}

Tumour samples were collected from 160 UK patients with pre-treated advanced esophageal or type I-II esophago-gastric junctional tumours. The majority of samples were diagnostic biopsies from the primary tumour (88.8\%), with surgical resection specimens accounting for $10.6 \%$ and one case $(0.6 \%)$ was from a diagnostic liver biopsy. Clinico-pathological features are summarised in Table 3.

\section{EGFR FISH analysis}

All FISH positive cases (EGFR amplified and high polysomy) scored by two independent observers were concordant (100\%). Sub-classification of FISH negative scores was also highly concordant, with a third scorer needed to agree classification in only $15 / 160$ cases (9.4\%).

Based on the classification criteria described in Table 2, $128 / 160(80.0 \%)$ of cases were classified as FISH negative and $32 / 160$ (20.0\%) were classified FISH positive. In the EGFR FISH negative group, disomy was present in 45 cases (28.1\%); low trisomy in $47(29.4 \%)$; high trisomy in two cases $(1.3 \%)$ and low polysomy in 34 cases $(21.3 \%)$. Of the EGFR FISH positive cases, high polysomy was in 
Table 2 EGFR FISH classification system adapted from

\begin{tabular}{ll} 
Varella-Garcia [35] & \\
\hline Tumour classification & EGFR status \\
\hline Disomy: $\leq 2$ copies in $\geq 90 \%$ cells & Negative \\
Low trisomy: $\leq 2$ copies in $\geq 40 \%$ cells, & Negative \\
3 copies in $10-40 \%$ cells, $: \leq 4$ copies in $<10 \%$ cells & Negative \\
High trisomy: $\leq 2$ copies in $\geq 40 \%$ cells, & \\
3 copies in $\geq 40 \%$ cells, $: \leq 4$ copies in $<10 \%$ cells & Negative \\
Low polysomy: $\geq 4$ copies in $10-40 \%$ cells & Positive \\
High polysomy: $\geq 4$ copies in $\geq 40 \%$ cells & Positive \\
Amplification: Any of & \\
-EGFR/CEP7 ratio $\geq 2$ & \\
- Small cluster (4-10 copies) or innumerable & \\
tight clusters in $>10 \%$ cells & \\
- Larger and brighter EGFR signals $v$ CEP7 signals & \\
in $>10 \%$ cells, with EGFR smaller than CEP7 in & \\
adjacent non-tumour cells & \\
- >15 copies of EGFR signal in $>10 \%$ tumour cells & \\
INDEPENDANT of EGFR/CEP7 ratio & \\
If amplified, pattern of amplification: \\
- Homogenous staining region (HSR) \\
- Double minute (DM)
\end{tabular}

displayed in $22(13.8 \%)$ cases and 10 (6.3 \%) cases harboured EGFR amplification (Fig. 1).

Three patterns of amplification were observed, double minutes, homogenous staining region and heterogeneous amplification (Fig. 1). Double minutes and homogenous staining regions in interphase have previously been described by Martin and colleagues [37]. Most amplified cases displayed uniform amplification with either a diffuse specked signal pattern consistent with double minutes or tightly packed signal clustering representing a homogenous staining region. A homogenous staining region is caused by amplicon clustering on a chromosome whereas double minute amplification is due to multiple copies of non-centromeric chromosomal fragments containing EGFR, seen as disseminated signals. Intra-tumoural heterogeneity for amplification was also observed, and tumours with $\leq 50 \%$ of cells exhibiting amplification were classed as heterogeneous amplification. Of the ten amplified cases, five were homogenous staining regions, three cases heterogeneously amplified and two were double minutes.

\section{Association of EGFR FISH status with clinical and pathological variables}

Using Fisher's exact test, no association was demonstrated between EGFR FISH status and gender $(p=0.752)$, disease site $(p=0.422)$, performance status $(p=0.085)$, body mass index $(p=0.737)$, brain metastases $(p=0.361)$ or number of prior chemotherapy regimens $(p=0.406)$ (Table 3$)$. No association was detected between central review of histology (one patient with baseline undifferentiated carcinoma was excluded from analysis) using Pearson $\mathrm{X}^{2}$ test $(p=0.909)$.

\section{Association between EGFR FISH status and survival}

In order to remove the effects of treatment interaction, the relationship between EGFR gene copy number and overall survival in the 79 of 160 patients that received no further treatment was examined. This allowed the therapy independent prognostic impact of EGFR FISH status to be examined in the population of advanced oesophageal cancers that have been, and most likely will be, evaluated in future clinical trials of anti-EGFR agents. There was no significant difference in overall survival in EGFR FISH positive $(N=14)$ versus negative $(N=65)$ patients, (HR $1.55,95 \%$ CI 0.85 to 2.85 , median overall survival $3.30 \mathrm{v} 3.03$ months $p=0.15$, Fig. 2), but there is limited power to detect anything except a large difference due to the small numbers. EGFR amplified cases $(N=5)$ had significantly worse overall survival compared to EGFR non-amplified cases $(N=74)$, (HR $2.64,95 \%$ CI 1.04 to 6.71 , median overall survival $1.76 \mathrm{v}$ 3.17 months, $p=0.03$, Fig. 2).

There was no significant difference in overall survival between EGFR FISH positive and EGFR FISH negative cases, or between EGFR amplified and non-amplified cases in the whole cohort and in patients that received a variety of further treatments (data not shown).

\section{Discussion}

In this study we successfully applied an EGFR FISH classification previously developed for non-small cell lung cancer, for use in esophageal cancer and characterised a series of 160 FFPE samples using dual colour probe EGFR FISH. Scoring in all FISH positive cases (amplified and high polysomy; 5 and 6) was concordant between two independent observers, and very high (90.6\%) for individual FISH negative categories 1 to 4, with concordance reached in all cases following third independent scorer analysis. Survival analysis in patients receiving best supportive care using this classification demonstrated worse prognosis in FISH amplified cases ( $p=0.03$ ).

In our series, $20 \%$ of EC patients were EGFR FISH positive, representing a significant subgroup of patients with advanced esophageal cancer with potential upregulation of and growth dependency upon the EGFR pathway. The frequency of EGFR amplification present in $6.3 \%$ (ten cases) is consistent with previous reports (6.25$49 \%)$ [23-32]. The frequency of FISH amplification is similar to that seen for the HER-2 receptor [28,38].

Three distinct patterns of amplification were observed, homogeneous staining regions representing large, bright 

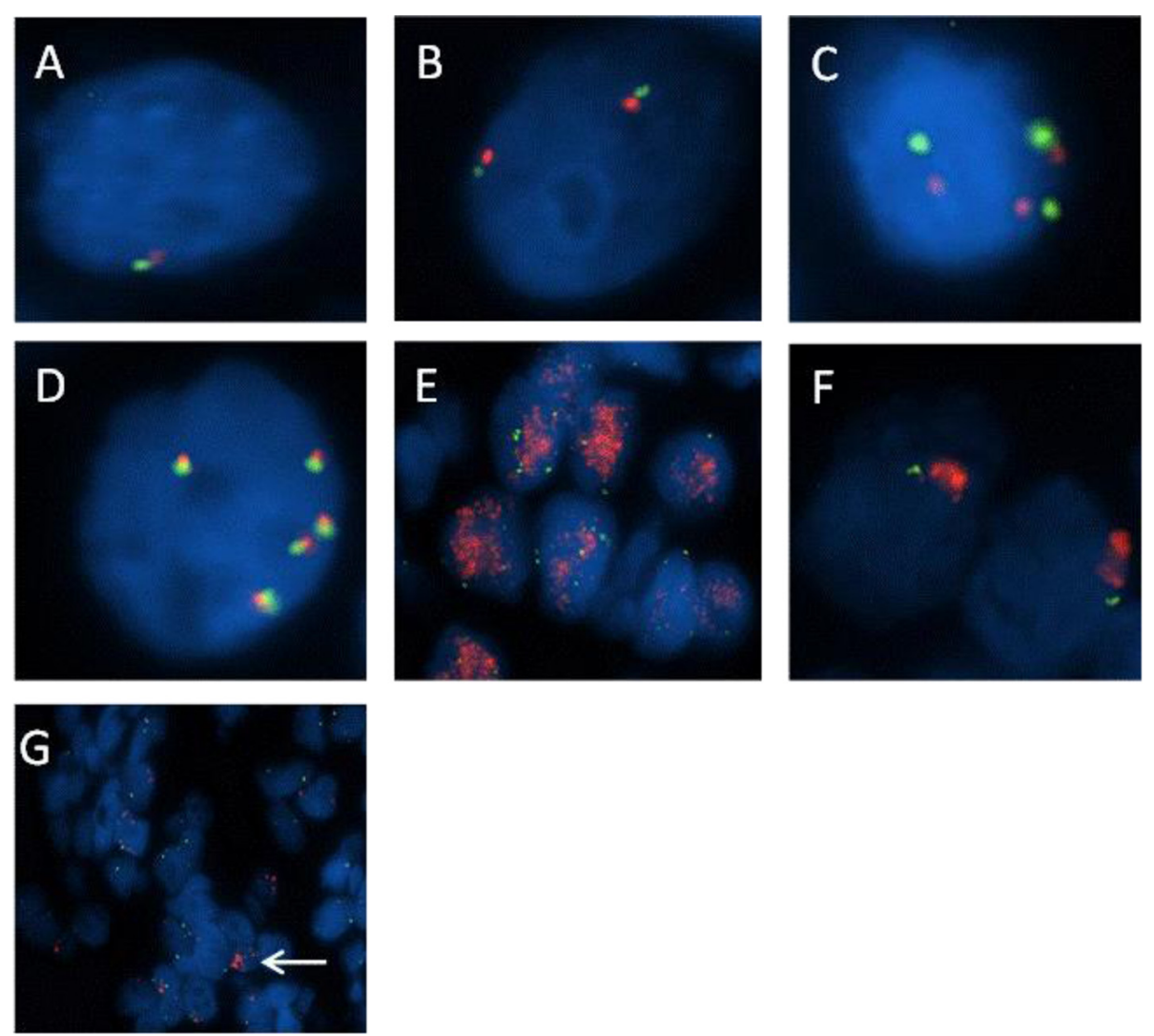

Fig. 1 EGFR FISH classifications and patterns of EGFR FISH amplification observed. Using dual colour FISH and fluorescent microscopy, EGFR gene copy number was determined in 160 patients with advanced oesophageal cancer. EGFR FISH negative cases are present in panels a-c, EGFR FISH positive cases in panels D-F and a heterogeneously amplified case in panel G. The EGFR FISH classification as follows: loss of chromosome 7 (a), disomy (b), trisomy (c), high polysomy (d), amplification (double minute type) (e), amplification (homogenous staining region type) (f) heterogeneous amplification ( $\mathbf{g}$ ). Blue = DAPI nuclear staining; red signal $=E G F R$; green signal = chromosome 7 centromere; white arrow $=E G F R$ amplified cells in a heterogeneous amplified case

signals caused by amplicon clustering; double minutes demonstrating fragments of non-centromeric chromosome material [37]; and heterogeneous amplification cases of both double minutes and homogeneous staining region type. Cases were felt to be heterogeneously amplified if $\leq 50 \%$ tumour cells demonstrated amplification. The issue of intratumoural heterogeneity remains controversial. Different cut-off values of $\leq 50 \%$ in gastric and $5-50 \%$ in breast cancers to define heterogeneous HER-2 amplification [39,40] have been applied and although EGFR copy number heterogeneity has been identified in non-small cell lung cancer [41] and colorectal cancer [42] no standardised classification system has been developed. Cases meeting our EGFR amplification criteria have significantly worse overall survival compared with non-amplified cases (median overall survival $1.76 \mathrm{v} 3.17$ months, $p=0.03$ ), in patients not treated with anti-cancer therapies, confirming EGFR amplification as a therapy independent prognostic biomarker in EC and supporting the use of dual colour EGFR FISH as a robust method of analysis of EGFR gene copy number.
Further studies are required to determine whether EGFR amplification in EC is useful as a predictive biomarker to identify patients suitable for anti-EGFR targeted therapy and we suggest that the method and scoring system described here is fit for this purpose.

A lack of standardised biopsies is a limitation of our study, the majority of tumour samples were from diagnostic biopsies of the primary tumour $(88.8 \%)$, surgical resection specimens accounted for $10.6 \%$ and one case $(0.6 \%)$ had a diagnostic biopsy from a metastatic hepatic deposit. Due to the invasive nature of endoscopy and biopsy, repeat tumour biopsies are rarely performed in this tumour type outside clinical trials or when patients are scheduled for surgery. Disease progression causing dysphagia requiring stent insertion is a potential opportunity for repeat biopsy, to differentiate, for example, stricture secondary to radiation induced fibrosis from tumour. Repeat endoscopies are not without risk and are considered intrusive for many patients and clinicians, particularly if it will not alter treatment options. 
Table 3 Association of EGFR FISH status with clinicopathological features

\begin{tabular}{|c|c|c|c|c|}
\hline & All patients $(N=160)$ & EGFR FISH negative $(N=128)$ & EGFR FISH positive $(N=32)$ & P value \\
\hline Age (mean,SD) & $64.02(9.49)$ & $64.15(9.64)$ & $63.49(8.99)$ & 0.725 \\
\hline \multicolumn{5}{|l|}{ Gender: } \\
\hline Male & $133(83.1 \%)$ & $10.7(80.5 \%)$ & $26(19.5 \%)$ & \multirow[t]{2}{*}{0.752} \\
\hline Female & $27(16.9 \%)$ & $21(77.8 \%)$ & $6(22.2 \%)$ & \\
\hline \multicolumn{5}{|l|}{ Histology: } \\
\hline Adenocarcinoma & $118(73.8 \%)$ & $94(79.7 \%)$ & $24(20.3 \%)$ & \multirow[t]{3}{*}{0.909} \\
\hline Squamous cell carcinoma & $41(25.6 \%)$ & $33(80.5 \%)$ & $8(19.5 \%)$ & \\
\hline Undifferentiated carcinoma & $1(0.6 \%)$ & $1(0.6 \%)$ & $0(0.0 \%)$ & \\
\hline \multicolumn{5}{|l|}{ Disease site: } \\
\hline Oesophagus & $124(77.5 \%)$ & $100(80.6 \%)$ & $24(19.4 \%)$ & \multirow[t]{3}{*}{0.422} \\
\hline Type I junctional & $16(10.0 \%)$ & $14(87.5 \%)$ & $2(12.5 \%)$ & \\
\hline Type II junctional & $20(12.5 \%)$ & $14(70.0 \%)$ & $6(30.0 \%)$ & \\
\hline \multicolumn{5}{|l|}{ WHO PS: } \\
\hline 0 (Asymptomatic) & $35(21.9 \%)$ & $32(91.4 \%)$ & $3(8.6 \%)$ & \multirow[t]{3}{*}{0.085} \\
\hline 1 (Symptomatic but ambulatory) & $91(56.9 \%)$ & 72 (79.1 \%) & 19 (20.9\%) & \\
\hline 2 (Symptomatic but resting $<50 \%$ of day) & $34(21.3 \%)$ & $24(70.6 \%)$ & $10(29.4 \%)$ & \\
\hline \multicolumn{5}{|l|}{ Body Mass Index category: } \\
\hline Underweight & $15(9.4 \%)$ & $13(86.3 \%)$ & $2(13.3 \%)$ & \multirow[t]{5}{*}{0.737} \\
\hline Normal & $83(51.9 \%)$ & $66(76.5 \%)$ & $17(20.5 \%)$ & \\
\hline Overweight & $37(23.1 \%)$ & $28(75.7 \%)$ & $9(24.3 \%)$ & \\
\hline Obese & $17(10.6 \%)$ & $15(88.2 \%)$ & $2(11.5 \%)$ & \\
\hline Missing data & $8(5.0 \%)$ & & & \\
\hline \multicolumn{5}{|l|}{ Brain metastases } \\
\hline No & $158(98.8 \%)$ & $127(80.4 \%)$ & $31(19.6 \%)$ & \multirow[t]{2}{*}{0.361} \\
\hline Yes & $2(1.3 \%)$ & $1(50.0 \%)$ & $1(50.0 \%)$ & \\
\hline \multicolumn{5}{|l|}{ No. of previous chemotherapies: } \\
\hline 1 & $103(64.4 \%)$ & $83(80.6 \%)$ & $20(19.4 \%)$ & \multirow[t]{3}{*}{0.406} \\
\hline 2 & $50(31.1 \%)$ & $38(76.0 \%)$ & $12(24.0 \%)$ & \\
\hline 3 & $7(4.4 \%)$ & $7(100.0 \%)$ & $0(0.0 \%)$ & \\
\hline
\end{tabular}

Abbreviations: WHO PS World Health Organisation Performance Status

Previous studies of EGFR copy number in EC are summarised in Table 1. A variety of techniques have been employed to investigate the frequency of EGFR copy number gain or amplification in esophagogastric cancer, yielding a frequency of $6.25-49 \%$ (Table 1) [16-25]. Of the studies using FISH to evaluate EGFR copy number change or amplification, two were in gastric cancer patients, demonstrating poor survival in the $4.88 \%$ of European patients with amplification, however survival outcome was not assessed in 29 \% EGFR amplified Chinese gastric cancer patients [24, 25]. In studies of EC where the prognostic impact of EGFR amplification by FISH has been assessed, there are discordant results, perhaps due to differing scoring criteria and histological tumour subtype [27-29, 31].
The distinct biological and molecular features of gastric cancer and EC, in particular the different frequencies of gene copy number changes, as well as the lack of a validated classification system for significant EGFR copy number gain or amplification, may account for inconsistencies in results. In addition, the majority of previous studies have been small and undertaken in patients of differing ethnicities and several studies were performed with technology that is no longer in widespread clinical use, making it unclear whether EGFR amplification does result in poorer survival.

The frequency of EGFR amplification may be lower in European and North American populations (6.5 -12.5\%) when compared to studies in Asian patients (7-49\%), implying a significant ethnic component to EGFR dysregulation in esophago-gastric cancer. Ethnic differences 


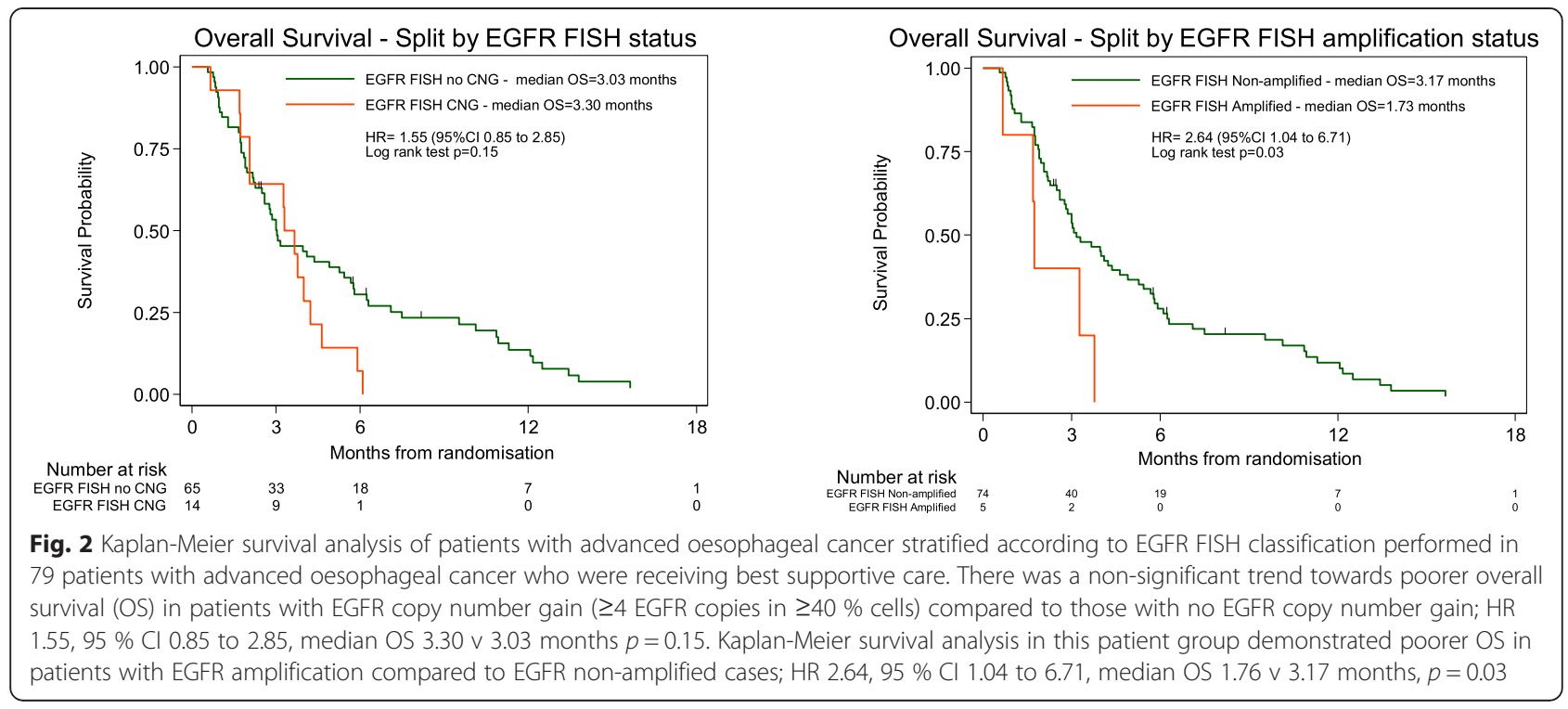

in molecular abnormalities have been identified in NSCLC where patients of Asian origin are more likely than Caucasians ( 35 v $11 \%$ ) to harbour the EGFR mutations inferring increased benefit from anti-EGFR therapy $[16,43,44]$.

The limited benefit and high toxicity of multi-agent cytotoxic chemotherapies in esophago-gastric cancer have prompted investigation of targeted therapies, including those targeting EGFR and HER-2. Trastuzumab, a monoclonal antibody against HER-2, has demonstrated activity in combination with platinum doublet chemotherapy in the 10-15\% patients with gastric cancer and tumour HER-2 protein overexpression or amplification, compared to chemotherapy alone [11].

The COG study of gefitinib, versus placebo in the second line setting of esophageal cancer patients did not demonstrate improvement in overall survival in unselected patients. Median progression free survival with gefitinib was significantly improved from 1.1 to 1.57 months (HR 0.8, $95 \%$ CI 0.66 to $0.96, p=0.02$ ) as was disease control rate, $24.1 \%$ compared to $15.6 \%$ at eight weeks $(p=0.016)$ [20]. The COG study results suggest that anti-EGFR tyrosine kinase inhibitor therapies represent a plausible therapeutic option for a sub-group of responsive patients. Accordingly, we propose that our scoring system should be used to explore the value of EGFR FISH positivity as a predictive biomarker for response to anti- tyrosine kinase inhibitor therapies, especially gefitinib [20].

\section{Conclusion}

In conclusion, we have shown that EGFR amplification assessed using our standardised FISH scoring system is a therapy independent prognostic biomarker of poor outcome in EC and represents a practical, robust assay useful for clinical research and clinical practice, particularly for investigation as a predictive biomarker for anti-EGFR therapies in clinical trials.

\section{Methods}

\section{Patient samples for FISH}

Ethical approval was obtained from the North of Scotland Research Ethics Committee. Esophageal tumour blocks from 160 patients with advanced EC who had received prior chemotherapy treatment were analysed (AJCC $7^{\text {th }}$ Edition, stage IIIB/C or IV), of which 81 went on to receive further systemic therapy [45]. Survival was measured in months from day of diagnosis until death. No analysis of EGFR expression was performed due to insufficient tumour tissue being available. Karyotype analysis was not possible as this was a retrospective study using archival formalin fixed paraffin embedded tissue.

\section{Fluorescence in situ hybridisation (FISH)}

Sections of $4 \mu \mathrm{m}$ thickness cut from FFPE esophageal tumour blocks were mounted on positively charged slides and pre-treated according to manufacturer instructions (Vysis Paraffin Pre-Treatment Reagent Kit II, Abbott laboratories, Maidenhead, UK). Briefly, slides were baked overnight at $50{ }^{\circ} \mathrm{C}$, then deparaffinised in xylene, followed by ethanol rehydration. They were then washed in Pre-Treatment solution for $10 \mathrm{~min}$ and deionised water for three minutes. Following this, slides were immersed in Protease Buffer II and Protease I solution (pepsin activity 1:3000-1:3500) for 25 min and after washing in de-ionised water, were dehydrated in an ethanol series. Once dry, $10 \mu \mathrm{l}$ of Vysis EGFR/CEP7 dual colour probe (Abbott Laboratories) was applied and a coverslip fixed using rubber cement. The slides were then transferred to a ThermoBrite StatSpin ${ }^{\circ}$ (Abbott laboratories) 
programmed to denature at $80{ }^{\circ} \mathrm{C}$ for six minutes, followed by hybridisation at $37^{\circ} \mathrm{C}$ for $16 \mathrm{~h}$.

Post- hybridisation, slides were washed in 2XSSC/0.3\% Igepal (Sigma-Aldrich Company Ltd Dorset, UK) and air dried in darkness. Once dried, nuclear counter stain containing 4,6-diamidino-2-phenylindole (DAPI) (Vectashield mounting medium, Vector Laboratories, Peterborough, UK) was applied, and a new cover slip was attached. Slides were stored in darkness at $4{ }^{\circ} \mathrm{C}$.

\section{FISH scoring}

Analysis was performed by two independent scorers, using a fluorescent microscope (AXIO Imager M1, Carl Zeiss Microscopy, Cambridge, UK) and images recorded using CytoVision 7.3.1 software (Leica Biosystems, Newcastle, UK). Three areas of tumour were examined, with 20 cells counted in each area. EGFR FISH scores were assigned for FISH negative: disomy (score $=1$ ), low trisomy $($ score $=2)$, high trisomy $($ score $=3$ ) and low polysomy (score $=4$ ) and for FISH positive: high polysomy (score $=5)$ and amplification (score $=6)$ (Table 2). In cases of discordance between the first two scorers, further analysis was carried out by a third independent scorer and agreement reached.

\section{Statistical analysis}

Relationships between baseline clinico-pathological features and EGFR mutation status were analysed using Pearson $\mathrm{Chi}^{2}$ or Fisher's exact test when cell counts were $\leq 5$. Hazard ratios with $95 \%$ confidence intervals, log rank test and Kaplan-Meier curves were constructed comparing overall survival, defined as time from diagnosis to death) and progression free survival (defined as time from diagnosis to progression or death) in EGFR FISH positive and negative cases, and EGFR amplified cases versus all other cases in the 79 patients who did not receive further systemic treatment for their disease. Statistical analysis was performed using Stata Version 13.1 (StataCorp LP, Texas, USA).

\section{Abbreviations}

EA: Esophageal adenocarcinoma; EC: Esophageal cancer; EGFR: Epidermal growth factor receptor; ESCC: Esophageal squamous cell carcinoma; FFPE: Formalin foxed paraffin embedded; FISH: Fluorescence in-situ hybridisation; HER-2: Human epidermal growth factor receptor 2.

\section{Competing interests}

ADS has received travel/ educational funding from Lilly and Boston Biomedical. DF has received research funding and gefitinib to run the COG study, both from Astra Zeneca. RDP has received research funding from Roche, Astra Zeneca, Life Technologies and Ahridia; travel/ educational funding from Bayer, Lilly, GSK and Sanofi; and has had an advisory role for Lilly, Bayer, Pzifer, and MSD. All other authors declare no competing interests.

\section{Authors' contributions}

The manuscript was drafted by ADS, DS, RDP and ZM. GIM reviewed the histopathology of all the cases. EGFR FISH was performed by ADS and EGFR FISH analysis was undertaken by ADS, DS and DM. SJD and CR carried out statistical analysis. All authors read and approved the final manuscript.

\section{Acknowledgements}

We thank the NHS Grampian Biorepository (Aberdeen Royal, Infirmary, Aberdeen, UK) for their assistance in sample storage and preparation.

\section{Author details}

'Division of Applied Medicine, University of Aberdeen, Aberdeen AB25 2ZD, UK. ${ }^{2}$ Department of Medical Genetics, Aberdeen Royal Infirmary, Aberdeen AB25 2ZD, UK. ${ }^{3}$ Department of Pathology, University of Aberdeen, Aberdeen AB25 2ZD, UK. ${ }^{4}$ Centre for Statistics in Medicine (CSM), Nuffield Department of Orthopaedics, Rheumatology and Musculoskeletal Sciences, University of Oxford, Botnar Research Centre, Windmill Road, Oxford OX3 7LD, UK. ${ }^{5}$ Eli Lilly and Company, 440 Route 22 East, Bridgewater, NJ 08807, USA. ${ }^{6}$ Department of Medical Genetics, University of Aberdeen, Aberdeen AB25 2ZD, UK.

Received: 18 June 2015 Accepted: 1 October 2015

Published online: 17 October 2015

\section{References}

1. Ferlay J, Shin H, Bray F, Forman D, Mathers C, Parkin D. GLOBOCAN 2008 V2.0, Cancer Incidence and Mortality Worldwide: IARC CancerBase No. 10 [Internet]. Lyon: International Agency for Research on Cancer; 2010. Available from: http://globocan.iarc.fr, accessed on 18 April 2013.

2. Edgren $G$, Adami $H$, Weiderpass $E$, Nyrén $O$. A global assessment of the oesophageal adenocarcinoma epidemic. Gut. 2013;62(10):1406-14.

3. Vizcaino AP, Moreno V, Lambert R, Parkin DM. Time trends incidence of both major histologic types of esophageal carcinomas in selected countries, 1973-1995. Int J Cancer. 2002;99(6):860-8.

4. Crew KD, Neugut Al. Epidemiology of upper gastrointestinal malignancies. Semin Oncol. 2004;31(4):450-64.

5. Ferlay J, Parkin DM, Steliarova-Foucher E. Estimates of cancer incidence and mortality in Europe in 2008. Eur J Cancer. 2010;46(4):765-81.

6. http://seer.cancer.gov/statfacts/html/esoph.html, accessed on 05 June 2014.

7. Gavin A, Francisci S, Foschi R, Donnelly D, Lemmens V, Brenner H, et al. Oesophageal cancer survival in Europe: A EUROCARE-4 study. Cancer Epidemiol. 2012;36(6):505-12.

8. Cunningham D, Starling N, Rao S, Iveson T, Nicolson M, Coxon F, et al. Capecitabine and oxaliplatin for advanced esophagogastric cancer. N Engl J Med. 2008;358(1):36-46.

9. Cromwell D, Palser T, van der Meulen J, Hardwick R, Riley S, Greenaway K, et al. National Oesophago-gastric Cancer Audit 2010. An audit of the care received by patients with Oesophago-Gastric Cancer in England and Wales: Third Annual Report. 2010.

10. Thallinger CM, Raderer M, Hejna M. Esophageal cancer: a critical evaluation of systemic second-line therapy. J Clin Oncol. 2011;29(35):4709-14.

11. Bang YJ, Van Cutsem E, Feyereislova A, Chung HC, Shen L, Sawaki A, et al. Trastuzumab in combination with chemotherapy versus chemotherapy alone for treatment of HER2-positive advanced gastric or gastrooesophageal junction cancer (ToGA): a phase 3, open-label, randomised controlled trial. Lancet. 2010;376(9742):687-97.

12. Neuzillet C, Tijeras-Raballand A, de Mestier L, Cros J, Faivre S, Raymond E. MEK in cancer and cancer therapy. Pharmacol Ther. 2014;141(2):160-71.

13. McCubrey JA, Steelman LS, Chappell WH, Abrams SL, Wong EW, Chang F, et al. Roles of the Raf/MEK/ERK pathway in cell growth, malignant transformation and drug resistance. Biochimica et Biophysica Acta (BBA)-Molecular. Cell Res. 2007;1773(8):1263-84.

14. Jorissen RN, Walker F, Pouliot N, Garrett TP, Ward CW, Burgess AW. Epidermal growth factor receptor: mechanisms of activation and signalling Exp Cell Res. 2003;284(1):31-53.

15. Normanno N, De Luca A, Bianco C, Strizzi L, Mancino M, Maiello MR, et al. Epidermal growth factor receptor (EGFR) signaling in cancer. Gene. 2006;366(1):2-16.

16. Mok TS, Wu YL, Thongprasert S, Yang CH, Chu DT, Saijo N, et al. Gefitinib or carboplatin-paclitaxel in pulmonary adenocarcinoma. N Engl J Med. 2009:361(10):947-57.

17. De Roock W, De Vriendt V, Normanno N, Ciardiello F, Tejpar SKRAS, BRAF. PIK3CA, and PTEN mutations: implications for targeted therapies in metastatic colorectal cancer. Lancet Oncol. 2011;12(6):594-603.

18. Lordick F, Kang YK, Chung HC, Salman P, Oh SC, Bodoky G, et al. Capecitabine and cisplatin with or without cetuximab for patients with previously untreated advanced gastric cancer (EXPAND): a randomised, open-label phase 3 trial. Lancet Oncol. 2013;14(6):490-9. 
19. Waddell T, Chau I, Cunningham D, Gonzalez D, Okines AF, Okines C, et al. Epirubicin, oxaliplatin, and capecitabine with or without panitumumab for patients with previously untreated advanced oesophagogastric cancer (REAL3): a randomised, open-label phase 3 trial. Lancet Oncol. 2013;14(6):481-9.

20. Dutton SJ, Ferry DR, Blazeby JM, Abbas H, Dahle-Smith A, Mansoor W, et al. Gefitinib for oesophageal cancer progressing after chemotherapy (COG): a phase 3, multicentre, double-blind, placebo-controlled randomised trial. Lancet Oncol. 2014;15(8):894-904.

21. Dulak AM, Stojanov P, Peng S, Lawrence MS, Fox C, Stewart C, et al. Exome and whole-genome sequencing of esophageal adenocarcinoma identifies recurrent driver events and mutational complexity. Nat Genet. 2013;45(5):478-86.

22. Petty RD. Exclusive rights in gastric cancer genomics. Gut. 2012;61(5):638-40.

23. Lemoine NR, Jain S, Silvestre F, Lopes C, Hughes CM, McLelland E, et al. Amplification and overexpression of the EGF receptor and c-erbB-2 proto-oncogenes in human stomach cancer. Br J Cancer. 1991;64(1):79-83.

24. $Y k$ W $, C f G, T Y, Z C, X W Z, X x L$, et al. Assessment of ERBB2 and EGFR gene amplification and protein expression in gastric carcinoma by immunohistochemistry and fluorescence in situ hybridization. Mol Cytogenet. 2011:4(1):14. 8166-4-14.

25. Kandel C, Leclair F, Bou-Hanna C, Laboisse CL, Mosnier JF. Association of HER1 amplification with poor prognosis in well differentiated gastric carcinomas. J Clin Pathol. 2014;67(4):307-12.

26. Itakura Y, Sasano H, Shiga C, Furukawa Y, Shiga K, Mori S, et al. Epidermal growth factor receptor overexpression in esophageal carcinoma. An immunohistochemical study correlated with clinicopathologic findings and DNA amplification. Cancer. 1994;74(3):795-804.

27. Sunpaweravong P, Sunpaweravong S, Puttawibul P, Mitarnun W, Zeng C, Baron $A E$, et al. Epidermal growth factor receptor and cyclin D1 are independently amplified and overexpressed in esophageal squamous cell carcinoma. J Cancer Res Clin Oncol. 2005;131(2):111-9.

28. Kato H, Arao T, Matsumoto K, Fujita Y, Kimura H, Hayashi $H$, et al. Gene amplification of EGFR, HER2, FGFR2 and MET in esophageal squamous cell carcinoma. Int J Oncol. 2013;42(4):1151-8.

29. Hanawa M, Suzuki S, Dobashi Y, Yamane T, Kono K, Enomoto N, et al. EGFR protein overexpression and gene amplification in squamous cell carcinomas of the esophagus. Int J Cancer. 2006;118(5):1173-80.

30. Janmaat ML, Gallegos-Ruiz MI, Rodriguez JA, Meijer GA, Vervenne WL, Richel DJ, et al. Predictive factors for outcome in a phase II study of gefitinib in second-line treatment of advanced esophageal cancer patients. J Clin Oncol. 2006:24(10):1612-9

31. Marx AH, Zielinski M, Kowitz CM, Dancau AM, Thieltges $S$, Simon R, et al. Homogeneous EGFR amplification defines a subset of aggressive Barrett's adenocarcinomas with poor prognosis. Histopathology. 2010;57(3):418-26.

32. Miller CT, Moy JR, Lin L, Schipper M, Normolle D, Brenner DE, et al. Gene amplification in esophageal adenocarcinomas and Barrett's with high-grade dysplasia. Clin Cancer Res. 2003;9(13):4819-25.

33. Hirsch FR, Varella-Garcia M, Bunn Jr PA, Di Maria MV, Veve R, Bremmes RM, et al. Epidermal growth factor receptor in non-small-cell lung carcinomas: correlation between gene copy number and protein expression and impact on prognosis. J Clin Oncol. 2003;21(20):3798-807.

34. Cappuzzo F, Varella-Garcia M, Shigematsu H, Domenichini I, Bartolini S, Ceresoli GL, et al. Increased HER2 Gene Copy Number Is Associated With Response to Gefitinib Therapy in Epidermal Growth Factor Receptor-Positive Non-Small-Cell Lung Cancer Patients. J Clin Oncol. 2005;23(22):5007-18

35. Varella-Garcia M. Stratification of non-small cell lung cancer patients for therapy with epidermal growth factor receptor inhibitors: the EGFR fluorescence in situ hybridization assay. Diagn Pathol. 2006;1:19.

36. Varella-Garcia M, Diebold J, Eberhard DA, Geenen K, Hirschmann A, Kockx M, et al. EGFR fluorescence in situ hybridisation assay: guidelines for application to non-small-cell lung cancer. J Clin Pathol. 2009;62(11):970-7.

37. Martin V, Mazzucchelli L, Frattini M. An overview of the epidermal growth factor receptor fluorescence in situ hybridisation challenge in tumour pathology. J Clin Pathol. 2009;62(4):314-24.

38. Deng N, Goh LK, Wang H, Das K, Tao J, Tan IB, et al. A comprehensive survey of genomic alterations in gastric cancer reveals systematic patterns of molecular exclusivity and co-occurrence among distinct therapeutic targets. Gut. 2012;61(5):673-84.
39. Tajiri R, Ooi A, Fujimura T, Dobashi Y, Oyama T, Nakamura R, et al. Intratumoral heterogeneous amplification of ERBB2 and subclonal genetic diversity in gastric cancers revealed by multiple ligation-dependent probe amplification and fluorescence in situ hybridization. Hum Pathol. 2014:45(4):725-34.

40. Vance GH, Barry TS, Bloom KJ, Fitzgibbons PL, Hicks DG, Jenkins RB, et al. Genetic heterogeneity in HER2 testing in breast cancer: panel summary and guidelines. Arch Pathol Lab Med. 2009;133(4):611-2

41. Grob TJ, Hoenig T, Clauditz TS, Atanackovic D, Koenig AM, Vashist YK, et al. Frequent intratumoral heterogeneity of EGFR gene copy gain in non-small cell lung cancer. Lung Cancer. 2013;79(3):221-7.

42. Ålgars A, Avoranta T, Österlund P, Lintunen M, Sundström J, Jokilehto T, et al. Heterogeneous EGFR Gene copy number increase is common in colorectal cancer and defines response to Anti-EGFR therapy. PLoS One. 2014;9(6):e99590.

43. Douillard JY, Shepherd FA, Hirsh V, Mok T, Socinski MA, Gervais R, et al. Molecular predictors of outcome with gefitinib and docetaxel in previously treated non-small-cell lung cancer: data from the randomized phase III INTEREST trial. J Clin Oncol. 2010;28(5):744-52.

44. Shepherd FA, Rodrigues Pereira J, Ciuleanu T, Tan EH, Hirsh V, Thongprasert S, et al. Erlotinib in previously treated non-small-cell lung cancer. N Engl J Med. 2005:353(2):123-32

45. Edge SB, Byrd DR, Compton C. AJCC Cancer Staging Handbook. 7th ed. New York: Springer; 2010

\section{Submit your next manuscript to BioMed Central and take full advantage of:}

- Convenient online submission

- Thorough peer review

- No space constraints or color figure charges

- Immediate publication on acceptance

- Inclusion in PubMed, CAS, Scopus and Google Scholar

- Research which is freely available for redistribution 